\title{
LOS DEBERES POSITIVOS GENERALES Y EL CONCEPTO DE «CAUSA»
}

\author{
Daniel González Lagier y Ángeles Ródenas \\ Universidad de Alicante
}

RESUMEN. En este trabajo se muestra la complejidad que se esconde tras un razonamiento aparentemente sencillo, empleado por Ernesto Garzón en su fundamentación de los deberes positivos generales, consistente en considerar fundada la existencia de un deber en el hecho de que la conducta contraria al mismo es la causa de un daño. Se muestra que este tipo de argumentos admiten varias interpretaciones y que todas ellas plantean inconvenientes: Puede asumirse una noción adscriptiva de causalidad que use criterios normativos para la imputación del status de causa, pero entonces el argumento se vuelve circular. En cambio, si se usa la regularidad fáctica como criterio de atribución, el argumento se frustra a sí mismo. La alternativa es «rebajar» la exigencia de una conexión causal a la exigencia de eficacia causal; pero entonces tenemos sólo la mitad del argumento: la otra mitad requiere un complejo razonamiento, de carácter esencialmente normativo. La conclusión final a la que llegan los autores es la de que fundamentar la existencia de los deberes positivos generales requiere, como en el caso de los deberes negativos generales, discutir abiertamente de normas, principios y valores.

Palabras clave: Ernesto Garzón Valdés, deberes positivos generales, causalidad.

ABSTRACT. This paper shows the complexity underlying the apparently simple argument used by Ernesto Garzón in order to justify general positive duties. This argument is based on the idea that the existence of a duty is justified because the opposite course of action causes harm. It is shown that this type of argument can be interpreted in different ways, and that all of these raise problems: If we take an adscriptive concept of cause, that is, a concept that uses normative criteria in order to impute the status of cause, then the argument becomes circular. In contrast, if we use factic regularity as a criterion of attribution, the argument defeats itself. The alternative is to lower the requirement from a causal connection to causal effectiveness; then, however we only have half of the argument: The other half requires complex reasoning of an essentialy normative nature. The authors reach the conclusion that in order to justify the existence of general positive duties the open discussion of norms, principles and values is required, as is the case with general negative duties.

Keywords: Ernesto Garzón Valdés, general positive duties, causality. 


\section{INTRODUCCIÓN}

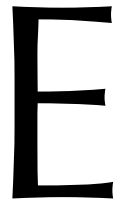

1 excelente e influyente artículo «Los deberes positivos generales y su fundamentación» ${ }^{1}$, de Ernesto GARZÓN VALDÉS, plantea uno de los problemas centrales de la teoría moral: la existencia, en pie de igualdad con los deberes negativos generales, de deberes positivos generales; esto es — de acuerdo con la definición que el autor ofrece en este artículo-, deberes «cuyo contenido es una acción de asistencia al prójimo que requiere un sacrificio trivial y cuya existencia no depende de la identidad del obligado ni de la del (o de los) destinatario(s) y tampoco es el resultado de algún tipo de relación contractual previa»².

Tras descartar diversos argumentos en contra de la equiparación entre ambos tipos de deberes, Ernesto GARZÓN adelanta un argumento positivo a favor de su fundamentación: en su opinión, y citamos textualmente, «[la] fundamentación de los deberes positivos generales es la misma que la de los deberes negativos generales: la protección de bienes que se consideran valiosos» ${ }^{3}$. Ernesto asume que los deberes positivos generales tendrían un «carácter eminentemente instrumental», lo que presupone que nuestras omisiones tienen algún tipo de relevancia causal para la producción de un estado de cosas que se considera disvalioso. Si la prohibición de ciertas omisiones, que es lo que hacen los deberes positivos generales, protege estos bienes primarios es porque se asume que existe una relación de causalidad entre tales omisiones y un daño (la lesión a los bienes primarios). Aunque el argumento de GARZÓN en defensa de la fundamentación de los deberes positivos generales es más complejo y tiene más matices, la existencia de esta relación de causalidad ocupa un lugar central en el mismo. Muestra de ello es la cita de John HARRIS que GARZÓN asume y con la que comienza el apartado de su artículo dedicado a la fundamentación, según la cual «No es la existencia de un deber lo que hace que la muerte de quien se está ahogando sea una consecuencia de que no le hayamos prestado auxilio sino que es más bien el hecho de que, a menos que lo auxiliemos morirá, lo que hace que auxiliarlo sea nuestro deber» ${ }^{4}$. En nuestra intervención, inspirados por el artículo de Carlos NINO «El cuatrilema del consecuencialismo» ${ }^{5}$, queremos explorar las distintas interpretaciones que pueden tener este tipo de argumentos en función del significado que se le asigne a la noción de «causa» que está detrás de ellos. Nuestra tesis es que este tipo de argumentos, o bien no son adecuados para fundamentar deberes o prohibiciones (pues llevan a diversas falacias), o bien esconden — como nos parece que es el caso en el artículo de Ernesto- un razonamiento complejo que involucra valores y ponderaciones que deben ser explicitados.

\section{2. «CAUSA» COMO NOCIÓN ADSCRIPTIVA}

En ocasiones se niega que las omisiones puedan tener eficacia causal. Es cierto, se dice, que las omisiones no interrumpen cursos causales, pero también lo es que no los

${ }^{1}$ Cfr. GARZÓN VALDÉs, 1986: «Los deberes positivos generales y su fundamentación», Doxa. Cuadernos de Filosofía del Derecho, n. ${ }^{\circ}$ 3, pp. 17-33.

${ }^{2}$ Cfr. GARZÓN VALDÉs, 1986: 17.

${ }^{3}$ Cfr. GARZÓN VAldÉs, 1986: 32.

${ }^{4}$ Cfr. Garzón Valdés, 1986: 31.

${ }^{5}$ NINO, 1987: «El cuatrilema del consecuencialismo», Doxa, n. ${ }^{\circ} 4$, pp. 365-366. 
ponen en marcha. Por ello, en sentido estricto no pueden ser causa de un resultado, o lo son en menor medida que las acciones. Ernesto GARZÓN rechaza acertadamente esta tesis aludiendo a la idea de un contexto integrado por diversas condiciones necesarias y conjuntamente suficientes del efecto, entre las cuales la omisión es una condición más. Escribe: «Cuando una omisión completa el contexto de las condiciones necesarias y suficientes, es tan causa como la acción que inicia la cadena causal» ${ }^{6}$. Ahora bien, si se parte de esta noción de causa como una condición más de un conjunto, entonces el problema surge cuando se trata de diferenciar a unas condiciones de otras, pues no consideramos «causa» a todas ellas.

Desarrollemos más esta idea. Si asumimos la aproximación a la noción de causa que subyace a la defensa que Ernesto GARZÓn hace de la relevancia causal de las omisiones, entonces una relación de causalidad se da entre un conjunto de condiciones, al que llamaremos contexto causal, y un determinado resultado o efecto. Sin embargo, el contexto causal puede ser muy amplio, pues una descripción completa del mismo debe hacer referencia a todos los estados de cosas que son condición necesaria del resultado o que están conectados (como condición necesaria o suficiente) con alguna condición necesaria del mismo. Para que Ticio mate a Cayo es preciso que los padres de Ticio lo hayan engendrado, pero, obviamente, este ancestral acto no puede ser considerado causa del crimen de Ticio, aunque es una condición necesaria del mismo. Por ello, para que un suceso sea considerado causa de un evento no basta con que sea una de las condiciones que integran el contexto causal, sino que, además, debe ser una condición en cierta manera cualificada. En realidad, hay que distinguir dos fases en la determinación de una relación causal entre dos eventos o sucesos $x$ e $y$. La primera fase es empírica, y consiste en mostrar que el evento $x$ forma parte del contexto causal que, de acuerdo con ciertas regularidades conocidas, da lugar al evento $y$. En otras palabras, estamos asumiendo que $x$ tiene (junto con el resto de condiciones del contexto) eficacia causal. La segunda fase tiene carácter atributivo o adscriptivo, es una imputación, y consiste en señalar a $x$ frente al resto de condiciones con eficacia causal como una condición especialmente relevante, lo suficiente como para individualizarla como causa de $y$. Sin embargo, relevante no quiere decir que tenga más eficacia causal o que sea más directa; cuando decimos, por ejemplo, que la causa del incendio fue una barbacoa mal apagada y descartamos como causa la presencia de oxígeno en el aire no es porque la primera tenga algo así como más «fuerza causal», sino porque la segunda es un suceso que, en algún sentido, no debería haber entrado en el contexto causal.

\section{LOS CRITERIOS DE ATRIBUCIÓN DEL STATUS DE CAUSA}

1. Hay varias maneras de entender la afirmación «el suceso $x$ no debería haber entrado en el contexto causal». La primera es claramente normativa, y consiste en entender que no debería significar que hay una norma que prohíbe el acto o la omisión de la que se trate. En este sentido, la noción de causa, en contextos en los que se dice $x$ causó $y$, es claramente normativa. Si cuando asumimos que hay una relación de causalidad entre la omisión de contribuir a paliar la situación de pobreza absoluta y algún

\footnotetext{
${ }^{6}$ Cfr. Garzón ValdÉs, 1986: 27.
} 
bien primario estamos asumiendo esa noción normativa de causalidad, entonces el argumento resulta circular, una petición de principio. Porque esa omisión sólo será la causa del resultado lesivo si existe una obligación de actuar, esto es, si existe el correspondiente deber positivo general. Esta vía no sirve para fundamentar los deberes positivos generales.

2. Otra posibilidad es buscar un criterio de atribución que no sea normativo, sino estrictamente empírico y evite así esta circularidad. Hay dos maneras de hacer esto. La primera es identificar «causa» con cualquiera de las circunstancias que forman parte del contexto causal; esto es, «causa» es cualquier condición con eficacia causal. Sin embargo, es obvio que esta alternativa da lugar a una noción tan amplia que resulta difícil encontrar un ámbito en el que sea útil. Pero para restringir la noción de causa aún nos queda otra alternativa: podemos entender el anterior no debería en un sentido dependiente de regularidades fácticas. Una condición resulta anormal (no debería estar) en un determinado contexto porque normalmente, como cuestión de hecho, no se da. Sin embargo, con esta noción de causa dependiente de regularidades, y no de normas, no se puede sostener que la omisión de ayudar a reducir la pobreza absoluta sea la causa de la lesión de ciertos bienes básicos, porque, lamentablemente, esta omisión, hoy día, no es una condición anormal (irregular) en el contexto, sino más bien lo contrario. Por tanto, esta vía tampoco es adecuada para fundar los deberes positivos generales.

\section{LA MERA EFICACIA CAUSAL COMO FUNDAMENTO DE UNA PROHIBICIÓN}

1. Existe todavía un recurso disponible para rescatar la idea de que ciertas conductas pasivas lesionan bienes primarios como fundamento para los deberes positivos. Se trata de sostener que lo relevante no es que omitir ciertas acciones se impute como causa de la lesión a los bienes primarios, sino que basta con constatar que tales omisiones tienen eficacia causal, esto es, que son una de las condiciones del resultado. Este argumento no identifica «causa» con «condición», sino que se limita a decir que, dado que ciertas omisiones son condición de la lesión de bienes primarios, estas omisiones deben estar prohibidas, con independencia de que sean consideradas o no como su causa. Es decir, la fundamentación de los deberes positivos generales descansaría en la primera fase, estrictamente empírica, de la determinación de una relación causal entre $x$ e y. Si no hemos entendido mal, ésta es la sugerencia de Juan Carlos BAYÓN en su artículo «Causalidad, consecuencialismo y deontologismo» ${ }^{7}$, en el que discute algunas tesis sostenidas por NINO en «El cuatrilema del consecuencialismo». Nos parece que es en esta clave en la que hay que entender la afirmación de John HARRIS — que Ernesto hace suya — de que es «el hecho de que, a menos que lo auxiliemos [una persona] morirá, lo que hace que auxiliarlo sea nuestro deber».

2. La cuestión es si la mera eficacia causal es un criterio adecuado para la corrección e incorrección moral. No siempre que una acción u omisión forman parte de un contexto causal nos parece fundamentado prohibirla, sobre todo en contextos causa-

7 BAYÓN, 1989: «Causalidad, consecuencialismo y deontologismo», Doxa. Cuadernos de Filosofía del Derecho, n. ${ }^{\circ}$ 6, pp. 461-500. 
les tan complejos como éstos: las condiciones con eficacia causal se conectan entre sí formando cadenas causales entre las que podríamos prohibir cualquier acción u omisión que fuera necesaria del resultado dañino. Si dos acciones u omisiones $x$ e $y$ son ambas condiciones necesarias del daño nos basta con suprimir una de ellas para evitarlo, por lo que no parece justificado prohibir las dos. ¿A cuál consideramos moralmente incorrecta y, por tanto, prohibimos? Es necesario contar con un criterio adicional; es decir, necesitamos desarrollar una argumentación que nos permita discriminar entre las condiciones con eficacia causal aquélla a la que consideramos moralmente incorrecta, independientemente de que se considere o no causa —en sentido estricto- del resultado. Éste sería un razonamiento que exigiría una ponderación entre el bien que se desea proteger y la lesión a otros bienes que la prohibición puede acarrear, así como un juicio acerca de la eficiencia instrumental de la prohibición y acerca de su menor lesividad frente a otras medidas igualmente eficaces. En definitiva, un juicio complejo y, en gran medida, normativo.

\section{CONCLUSIONES}

Lo que hemos pretendido con los razonamientos anteriores es mostrar la complejidad que se esconde tras un argumento aparentemente sencillo, consistente en considerar fundada la existencia de un deber en el hecho de que la conducta contraria al mismo es la causa de un daño. Hemos visto que este tipo de argumentos admiten varias interpretaciones. Si se asume una noción adscriptiva de causalidad que use criterios normativos para la imputación del status de causa, entonces el argumento se vuelve circular. Si usamos la regularidad fáctica como criterio de atribución, el argumento se frustra a sí mismo. La alternativa es «rebajar» la exigencia de una conexión causal a la exigencia de eficacia causal; pero entonces tenemos sólo la mitad del argumento: la otra mitad requiere un complejo razonamiento, de carácter esencialmente normativo. Desarrollarlo es una tarea urgente para quienes deseamos defender la fundamentación de los deberes positivos generales. 